\title{
The Role of Nuclear Matrix Attachment Regions in Plants
}

\author{
George C. Allen
}

\begin{abstract}
Regions of DNA that bind to the nuclear matrix, or nucleoskeleton, are known as Matrix Attachment Regions (MARs). MARs are thought to play an important role in higher-order structure and chromatin organization within the nucleus. MARs are also thought to act as boundaries of chromosomal domains that act to separate regions of gene-rich, decondensed euchromatin from highly repetitive, condensed heterochromatin. Herein I will present evidence that MARs do indeed act as domain boundaries and can prevent the spread of silencing into active genes. Many fundamental questions remain unanswered about how MARs function in the nucleus. New findings in epigenetics indicate that MARs may also play an important role in the organization of genes and the eventual transport of their mRNAs through the nuclear pore.
\end{abstract}

\section{Introduction}

For many years it has been known that the expression of a transgene in eukaryotic organisms can vary widely between independent transformants (Allen et al. 1988). The unpredictable, varied expression found in transgenic plants has been called "chromosomal position effects," and is attributed to the characteristics of the site of integration (Alberts and Sternglanz 1990; Dean et al. 1988; Nagy et al. 1985). Chromosomal position effects are primarily due to transgene integration events that can occur within euchromatin, which contains the majority of expressed genes, or condensed chromatin, such as heterochromatin (reviewed in Taddei et al. 2004). The pre-existing chromatin structure at the site of integration ultimately determines the transgene expression level, either negatively (silenced) or positively (enhanced). Transgene expression can be highly variable since transgene integration cannot yet

G.C. Allen

North Carolina State University, Department of Horticultural Science, 1203 Partners 2,

Campus Box 7550, Raleigh, NC 27606-7550, USA

e-mail: george_allen@ncsu.edu 
be easily targeted to a specific genomic location with a favorable chromatin structure.

There are many examples that complicate both the use of transgenes as research tools and their application in plant-improvement programs (De Neve et al. 1999; Gepts 2002; James et al. 2004). Variability due to silencing and related processes requires the evaluation of many transformation "events," or independent transformants, in order to interpret the phenotypic effects of transgenes. This, in turn, increases the cost of labor and cause for regulatory concern. Because silencing can occur spontaneously in later generations of lines initially showing good expression, selecting stably expressing lines from a population of independent transformants, or even from the T1 generation, does not guarantee stability of expression over subsequent generations (Bourdon et al. 2002; Bregitzer and Tonks 2003; Chareonpornwattana et al. 1999; Levin et al. 2005; Vain et al. 2002). In order to avoid major problems, a number of candidate lines must be maintained through multiple generations before it is possible to select those showing stable and predictable expression.

In this chapter I explore ideas why MARs ${ }^{1}$ improve the transformation frequency and reliability of transgene expression in some cases but seem to have no effect in other cases. I discuss practical strategies for preventing undesirable gene silencing and provide examples showing that MARs are, counterintuitively, beneficial for enhancing transgene RNA silencing (RNAi) when a gene knockout (knockdown) is desired. I also describe the other critical roles that MARs play in regulating nuclear structure and genome organization, beyond their role in gene expression.

In order to understand several controversial ideas regarding MARs it is important to understand the nuclear matrix, which is also known as the nuclear scaffold, or nucleoskeleton. A detailed description of the nucleoskeleton is provided in an accompanying chapter in this book by Moreno Diaz de la Espina. It is thought that the effect of MARs on gene expression is achieved through their impact on chromatin structure. I briefly describe the role of histone modifications with particular emphasis upon the replacement histone H2A.Z. Increasingly, such histone variants are being recognized as mediators that can act in concert with boundary elements to separate active from inactive chromatin. The reader is also referred to accompanying chapters in this book that describe work on nuclear pores (A. Rose) and on chromatin domains (P. Fransz).

\footnotetext{
${ }^{1}$ It is important to note that during the past twenty 20 plus years various nomenclature have been used for MARs which include Scaffold Attachment Region (SAR) (Allen et al. 1996; Bode and Maass 1988), Boundary Elements (Cuvier et al. 2002; Mlynarova et al. 2003; Pathak et al. 2007), certain types of Chromatin Insulators (Istomina et al. 2003; Valenzuela and Kamakaka 2006), or a combination of both (S/MAR) (Goetze et al. 2005; Heng et al. 2004). These terms are used interchangeably throughout this chapter.
} 


\subsection{Chromosomal Loop Domains}

Early studies with animal cell lines demonstrated that the "chromosomal position effect" could be prevented if the transgene was flanked by "Matrix Attachment Regions" (MARs ${ }^{2}$ ), which are DNA elements that bind to the nuclear matrix ${ }^{3}$ (Mirkovitch et al. 1984). Electron microscopy studies from Paulson and Laemmli (1977) provided an elegant demonstration that when the core histones are removed, DNA from metaphase chromosomes becomes unpackaged and reveals higher-order structure. A series of large DNA loops is bound at their bases to a core structure, which had been identified earlier as the nuclear matrix by Berezney and Coffey (1974). When the data from higher-order structure was combined with gene expression studies, a new model, known as the loop domain model, was developed (Bodnar 1988; Cockerill and Garrard 1986; Cook 1989; Gasser and Laemmli 1986; Stief et al. 1989).

According to the loop domain model, MARs act as a barrier to the effect of surrounding chromatin (Fig. 1). When applied to transgenic plants, this model would effectively make the transgene domain independent. A major prediction of the loop domain model is that a transgene, flanked by the "protecting" MARs, remains active independently of the local chromatin state. A corollary prediction is that transgenes lacking MARs are susceptible to the impact of the surrounding chromatin structure and their expression level is dependent upon the local chromatin state. By acting independently, each transgene domain would contribute equally to transgene expression, which would increase in proportion to the number of transgenes. Thus, if more copies of a MAR-flanked transgene are integrated, a proportional increase in the expression of the transgene will result. Such predictions made from the loop

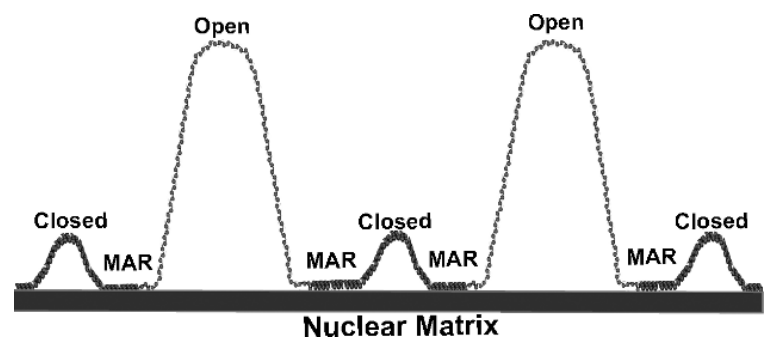

Fig. 1 Loop domain model. Active genes are within the open loops with an open chromatin structure. The open loops are bounded at their base by Matrix Attachment Regions (MARs) that bind to the nuclear matrix (grey). The chromatin structure at the MAR is in a transition zone that separates the open loop from the closed loops. The closed loops contain compact nucleosome

\footnotetext{
${ }^{2}$ MARs also called SARs (Scaffold Attachments Regions) or S/MARs.

${ }^{3}$ Nuclear matrix is also called nucleoskeleton or nuclear scaffold.
} 
domain model were supported by the results from the early animal cell studies in which transgenes flanked by MARs from either the human $\beta$-globin gene (Grosveld et al. 1987) or the chicken lysozyme A-element (Phi-Van et al. 1990; Stief et al. 1989) resulted in transgene expression that was proportional to transgene number.

\section{The Role of MARs in Higher-Order Chromatin Structure in the Plant Nucleus}

\subsection{Packaging the Genome}

\subsubsection{DNase I Sensitive Sites}

Genomic DNA must be carefully folded in an organized manner in order to fit within the interphase nucleus. The packaging of chromatin is accomplished at several levels starting with the interaction of double-stranded DNA with two molecules of each of the core histones $\mathrm{H} 2 \mathrm{~A}, \mathrm{H} 2 \mathrm{~B}, \mathrm{H} 3$, and $\mathrm{H} 4$ to form the 11-nm chromatin fiber. The 11-nm fiber is further packaged by interacting with $\mathrm{H} 1$, the linker histone, to form the condensed 30-nm nucleosome. The details of the subsequent packaging steps to form the higher-order condensed structures are still largely unknown. It is generally thought that chromatin loops of up to $300 \mathrm{~nm}$ are bound at their base by MARs to a non-histone protein-RNA core, which is believed to be the nuclear matrix as shown in Fig. 2. When the core histones are removed, the 300-nm loops are unpackaged. Measurements by Paulson and Laemmli (1997) estimated that these histone-free loops averaged 10-12 $\mu \mathrm{m}$ in length in Drosophila metaphase chromosomes, which represents an increase in length of 30-40-fold.

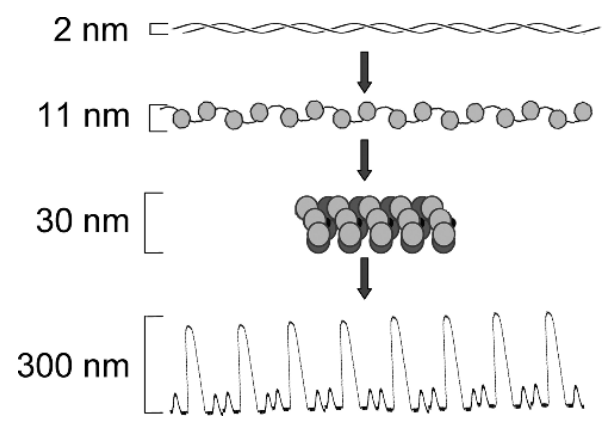

Fig. 2 Chromatin packaging. The packaging of chromatin is accomplished at several levels starting with the interaction of double-stranded DNA with two molecules of each of the core histones $\mathrm{H} 2 \mathrm{~A}, \mathrm{H} 2 \mathrm{~B}, \mathrm{H} 3$, and $\mathrm{H} 4$ to form the 11-nm chromatin fiber. The 11-nm fiber is further packaged by interacting with $\mathrm{H} 1$, the linker histone, to form the condensed 30-nm nucleosome. It is generally thought that chromatin loops of up to $300 \mathrm{~nm}$ are bound at their base by MARs to a nonhistone protein-RNA core, which is believed to be the nuclear matrix 
The different levels of chromatin structure can shorten a double-stranded molecule of DNA by up to 50,000-fold (Alberts et al. 2002).

When a gene is activated, the chromatin structure becomes less compact and the DNA becomes more accessible to DNase I (Spiker et al. 1983; Weintraub and Groudine 1976). MARs are thought to function as the boundaries of the chromatin loop domains and to demarcate active chromatin from inactive chromatin (Bode and Maass 1988; Bonifer et al. 1991; Gasser and Laemmli 1986; Gromova et al. 1995). Paul and Ferl (1998) used differences in chromatin accessibility to DNase I to compare the higher-order chromatin structure in both Arabidopsis and maize nuclei. They found that DNase I cleavage at "super-hypersensitive" sites resulted in domains that averaged $45 \mathrm{~kb}$ for maize and $25 \mathrm{~kb}$ for Arabidopsis. They proposed a model that these larger domains represent a fundamental structural loop domain bound to the nuclear matrix at "loop basements," or LBARs.

It is now well recognized that gene-coding sequences alone do not provide answers to how the genome is regulated. A new effort to understand the function of the epigenome (Crawford et al. 2006) has been initiated with the goal of understanding the function of the non-coding regions of the human genome, which includes mapping the DNase I hypersensitive sites using tiled microarrays (Giresi and Lieb 2006; Sabo et al. 2006). Because of the size of the human genome, researchers are limited to focusing on selected regions, which only encompass approximately $1 \%$ of the entire genome (Greally 2007). In contrast, Arabidopsis, with such a small genome, offers tremendous advantages for such studies. In principle, either entire chromosomes or even the entire genome could be studied in detail. Unfortunately, while the analytical capability does exist, the mapping of DNase I hypersensitive sites in Arabidopsis has to date been limited to relatively small regions.

Kodama et al. (2007) mapped DNase I hypersensitive sites in an 80-kb region from Chromosome 5 of Arabidopsis thaliana that contains 30 genes with expression levels that vary greatly. A total of 40 DNase I hypersensitive sites were found and all were located at the $5^{\prime}$ and $3^{\prime}$ ends of 28 of the 30 genes. These data suggest that the average size of a DNase I "hypersensitive domain" within the 80 -kb region is $\sim 2 \mathrm{~kb}$. If such DNase I hypersensitive sites found by Kodama et al. (2007) represent true chromosomal domains, then the size is much smaller than the DNase I hypersensitive domains found in either animal studies or even the $25-\mathrm{kb}$ estimate for Arabidopsis by Paul and Ferl (1998). It is important to note that the apparent difference in DNase domain size may simply be due to the use of an 80-kb region (Kodama et al. 2007) versus a 130,000-kb region (Paul and Ferl 1998). Furthermore, the Kodama et al. (2007) result seems to differ from previous studies that show that DNase I hypersensitivity varies depending upon the expression of the gene. For example, Vega-Palas and Ferl (1995) note that DNase I-hypersensitive sites in the $5^{\prime}$ flanking region of transcriptionally active genes are associated with the presence of transcriptional regulatory factors, which also reflects a de-condensation of the chromatin. Although more studies will certainly follow, the Kodama et al. study suggests that DNase I hypersensitivity does not reflect transcriptional activity, which is likely to be controversial. 


\subsubsection{MARs and Histone Modification}

In eukaryotic nuclei the domains defined by differences in DNase I sensitivity are also characterized by the differences in post-translational modifications of the histones within the domain. Histone modifications within DNase I-accessible and transcriptionally active domains are typically characterized by hyperacetylation and di- or trimethylation of the lysine- 4 of H3. Conversely, transcriptionally inert or inactive chromatin is tightly packaged and thus insensitive to DNase I, and the lysine-9 of H3 is hypoacetylated and methylated (Johnson et al. 2002; Soppe et al. 2002; Tamaru and Selker 2001; and reviewed in Tariq and Paszkowski 2004). Whole genome analysis of Arabidopsis using Chromatin Immunoprecipitation (ChIP) analysis has confirmed that transcriptionally active regions are highly enriched with $\mathrm{H} 3$ lysine-4 di- or trimethylation, whereas inactive heterochromatic regions are enriched in $\mathrm{H} 3$ lysine-9 trimethylation (Gendrel et al. 2005).

As noted earlier, MARs, or boundary elements, are proposed to define chromosomal domains and to prevent transcriptionally active regions from being silenced by the spread of condensed heterochromatic regions (Martienssen 2003). While it is now clear that the inactive and active chromosomal domains are enriched in specific forms of modified histones, it is not known what type of histone is actually associated with MARs. The Grey lab has dissected the chromatin structure of the pea PET gene and the initial studies identified a downstream MAR region (Slatter et al. 1991). Further studies identified an A/Trich region in the promoter that bound to High Mobility Group I/Y (HMG) proteins (Pwee et al. 1994). Transgenic plant studies showed that the A/T-rich region enhanced the expression of a b-glucuronidase (GUS) reporter gene and that when the 31-bp A/T core was included, the reporter gene expression also increased (Sandhu et al. 1998). Chua et al. (2001) then tested the pea PetE locus for changes in nuclease sensitivity and $\mathrm{H} 3$ and $\mathrm{H} 4$ acetylation during three different transcriptional states (roots, etiolated shoots, and green shoots). As expected, the DNase I sensitivity increased during activation, and H3 and H4 from PetE were hyperacetylated in the green shoots, and were particularly enriched in the promoter/enhancer region.

A subsequent study by Chua et al. (2003) found that the A/T-rich transcriptional enhancer of the pea Petl bound to the nuclear matrix when either an in vitro binding assay or in vivo enrichment in the matrix fraction in the transgenic tobacco was used. Because MARs are defined as DNA elements that bind the matrix, this enhancer was also a MAR. Transgenic tobacco transformed with an enhancer Pet1 promoter fragment controlling GUS (E-Pet1:GUS) had higher GUS expression levels than the plants transformed with the same construct lacking the enhancer (Pet1:GUS). Differences in the $\mathrm{H} 3$ and $\mathrm{H} 4$ acetylation patterns reflected the expression differences with the pea EPet1:GUS transformants showing increased levels of $\mathrm{H} 3$ and $\mathrm{H} 4$ acetylation that spread into the $5^{\prime}$ end of $G U S$. These data are consistent with a model for MARs being associated with open chromatin that has the increased $\mathrm{H} 3$ and $\mathrm{H} 4$ acetylation patterns expected for active genes. 


\subsubsection{The Transition Zone: MARs, Boundaries and Histone Variants}

Studies to understand the transition, or boundary zone between inactive and active chromosomal domains have become increasingly important as intergenic, noncoding genomic regions are recognized for controlling critical processes such as transcription, DNA replication, cell division, differentiation, and development. In the popular press the genome sequence and how it is regulated has been compared to a computer; with the primary sequence referred to as the hardware and the epigenome referred to as the software. While changes in genomic sequence are generally thought to occur slowly, changes to the epigenome can occur rapidly, which may help the organism to readily adapt to environmental change.

It is now known that nearly the entire genome is transcriptionally active, which includes non-coding regions that can produce regulatory RNAs. These results were initially found using the fission yeast Schizosaccharomyces pombe (Hall et al. 2002; Volpe et al. 2002) and showed that centromeric heterochromatin is maintained by RNAi. The same, or a closely related mechanism is also responsible for forming (Martienssen 2003; Zilberman et al. 2004) or maintaining (Gendrel et al. 2002; May et al. 2005) heterochromatin in higher eukaryotes (reviewed by Henderson and Jacobsen 2007; Lippman and Martienssen 2004; Martienssen et al. 2005; Zaratiegui et al. 2007). However, major questions remain regarding the composition and regulation of genomic boundary regions and how they function to separate the active from inactive chromosomal domains, preventing the spread of transcriptionally inactive, condensed chromatin into the transcriptionally active, de-condensed chromatin.

The process of how gene silencing spreads has been an enigma for many years. It is well known that the proximity of a transgene integration site to heterochromatin can result in silencing of the transgene (Assaad et al. 1993; Dorer and Henikoff 1997; and reviewed in Henikoff 1998 and Jacobsen 1999). In addition, the organization of a transgene locus also is known to play a major role, particularly when multiple copies integrate at a single site (Jorgensen et al. 1996; Stam et al. 1997; and reviewed in Allen et al. 2000 and Thompson et al. 2006). For instance, most transgene integrations that result in an inverted repeat structure become silenced and form condensed chromatin (Martienssen 2003; Muller et al. 2002; Pecinka et al. 2005). Condensed chromatin is thought to be able to spread by a self-propagated RNAi-mediated process, unless it is physically blocked by either a bound protein or a change in the chromatin structure (Bi et al. 2004; and reviewed in Richards and Elgin 2002; Talbert and Henikoff (2006); and Gaszner and Felsenfeld 2006).

Recent studies in budding yeast (Saccharomyces cerevisiae) have shown that the histone variant $\mathrm{H} 2 \mathrm{~A} . \mathrm{Z}$ is found at the transition zones between active and inactive chromatin (Meneghini et al. 2003). Nucleosomes that include both histone variants H2A.Z (H1Z in S. cerevisiae), and another variant, H3.3, are more susceptible to disruption (Jin and Felsenfeld 2007), leading to an increase in local chromatin accessibility. Of particular interest is the finding by Meneghini et al. (2003) that the interaction of H2A.Z with boundary elements can act synergistically to block the spread of heterochromatin. To date, the only studies to demonstrate the H2A.Z-insulator block 
have been done in $S$. cerevisiae. While the role of H2A.Z is less clear in higher eukaryotes (Wong et al. 2007), it is necessary for viability in Tetrahymena thermophila, Drosophila melanogaster, and mice (Sarcinella et al. 2007).

Arabidopsis thaliana H2A.Z (H2A.F/Z) is highly conserved (Kamakaka and Biggins 2005; Meneghini et al. 2003) and appeared very early in evolution (Callard and Mazzolini 1997). This raises the possibility that Arabidopsis H2A.Z may have retained similar functions, to bind to boundary elements and block the spread of heterochromatin. In yeast, H2A.Z $(\mathrm{H} 1 \mathrm{Z})$ is a replacement histone for $\mathrm{H} 2 \mathrm{~A}$. The replacement is catalyzed by SWR1C, a member of the SWI2/SNF2 superfamily with orthologs in Arabidopsis. In Arabidopsis, flowering in long day conditions is contingent upon the successful establishment of epigenetic silencing of $F L C$, a repressor of the transition to flowering. This is achieved by histone trimethylation at $\mathrm{H} 3$ lysine 27 and deacetylation and is maintained by proteins that establish a Polycomb-like chromatin regulation (Greb et al. 2007). Mutations in FLC cause early flowering, the same phenotype as various mutants of Arabidopsis thaliana with defective SWRIC (Choi et al. 2007). Deal et al. (2005) showed that mutations in SUF3 (ARP6 in yeast), which is a nuclear actin-related protein and also part of the SWR1 chromatin remodeling complex, also result in an early flowering phenotype, similar to the FLC mutations. Finally, studies by Deal et al. (2007) showed that Arabidopsis thaliana H2A.Z is required to suppress flowering by activating $F L C$. Such observations that H2A.Z potentiates transcription are similar to the proposed role of $\mathrm{H} 1 \mathrm{Z}$ in the yeast.

\subsubsection{Do MARs and Boundary Elements Associate with the Nuclear Pore Complex?}

The nuclear pore allows communication between the interior of the interphase nucleus and the exterior cytoplasm, as described in detail in a separate chapter in this book (A. Rose). It is generally assumed that mRNA must be exported in order to be transcribed but given the packaging constraints of nuclear DNA, mRNA export is unlikely to occur by simple diffusion or stochastic interactions. Here I briefly describe a possible role for the nuclear pore in the localization of active genes (Aguilera 2005; Cabal et al. 2006; Casolari et al. 2004; Ishii et al. 2002; Taddei et al. 2006). In yeast, mRNA transport from an actively transcribing gene has been shown to "track" from the nuclear interior to the nuclear pore. However, data from recent studies with both yeast and Drosophila have also shown that chromatin redistribution or movement may contribute to the transport process. H2A.Z has been proposed to facilitate this process providing active genes access to the nuclear pore. The molecular intermediates that control this process could interact with MARs or use MARs as a type of DNA tether to shuffle parts of the chromosome into territories with access to a nuclear pore.

Data from a recent study by Brickner et al. (2007) indicate that H2A.Z can interact with promoter regions of an active gene, thereby localizing the genes to the nuclear pore. Interestingly, even recently repressed genes retain bound H2A.Z 
and remained associated with the nuclear pore complex (NPC). Chromatin immunoprecipitation (ChIP) experiments have been used to show that transcriptionally active genes can occur in a complex that includes components of the nuclear pore complex, such as Nup2. Brickner et al. (2007) suggest that Nup2 may recruit or "tether" H2A.Z and its associated genes, to the nuclear pore to enable rapid reactivation (Dilworth et al. 2005; Ishii et al. 2002). Such "tethering" may promote boundary activity, thus preventing the spread of condensed chromatin into transcriptionally poised regions. Brickner et al. (2007) also note that previous data with mutants lacking either H2A.Z, or Nup2 show an increase in the spread of silent chromatin (Dilworth et al. 2005; Meneghini et al. 2003). Boundary elements are thought to associate with the NPC, allowing active genes to be correctly positioned for either active transcription or to be poised for transcription. Thus, H2A.Z binding allows for both proper localization of a gene to the NPC, and proper demarcation of heterochromatic silencing by its interaction with boundary elements. Furthermore, by remaining associated with recently active chromatin, H2A.Z confers epigenetic memory (Brickner et al. 2007).

One caveat that remains to be addressed is that all of the studies that have shown $\mathrm{H} 2 \mathrm{~A} . \mathrm{Z}$ association with the nuclear pore have been done in S. cerevisiae. While most of the cellular processes that are found in S. cerevisiae also occur in higher eukaryotes, there are a few important exceptions. In addition to the small size of its genome and nucleus, post-transcriptional gene silencing appears to be lacking in S. cerevisiae while some form of this silencing occurs in almost all other eukaryotes, including quelling in fungi (Valenzuela and Kamakaka 2006). Additionally, homologous recombination readily occurs in $S$. cerevisiae. Although many questions remain from the $S$. cerevisiae studies, the process is thought to be highly conserved across eukaryotes (Cole and Scarcelli 2006; Ragoczy et al. 2006). Taken together as a general model, tethering of active or recently active gene regulatory regions by MAR-bound proteins, such as H2A.Z, to the NPC may both block the spread of condensed chromatin and facilitate the transport of mRNA from the nucleus. However, questions will remain until experiments are done in plants to directly test this model.

\section{The Use of MARs to Prevent Transgene Silencing}

\subsection{MARs and Transgene Expression}

Encouraging results from animal studies (Grosveld et al. 1987; Phi-Van et al. 1990; Stief et al. 1989) suggested that MAR-flanked transgenes would be an important tool for preventing chromosomal position effects in plants (Allen et al. 1993, 1996; Breyne et al. 1992; Mlynarova et al. 1994; Schoffl et al. 1993). A diversity of promoters and MAR sequences have been used to test the level of expression of the $\beta$-glucuronidase (GUS) reporter gene. Allen et al. (1993) used the GUS gene driven by the strong CaMV 35S promoter, which was flanked by either the 
yeast ARS-14 (Allen et al. 1993), which is known to be a MAR (Amati and Gasser 1988), or a tobacco MAR from the Rb7-3 gene (Allen et al. 1996; Hall et al. 1991). Breyne et al. (1992) used GUS driven by the weaker nopaline synthase promoter and MARs from either the soybean lectin gene or the human $\beta$-globin locus to flank the transgene cassette. Mlynarova et al. (1994) used a GUS reporter gene driven by the promoter from apoprotein 2 of the light harvesting complex of photosystem I of the potato (Lhca3) promoter, which was flanked by MARs from the chicken lysozyme A element. Schoffl et al. (1993) also used a GUS reporter transgene, which was controlled by the heat-shock inducible promoter from the heat-shock inducible Gmhsp17.3-B gene from soybean. A 395-bp MAR from a different soybean heat shock gene (Gmhsp 17.6L) flanked the transgene cassette.

When NT1 tobacco suspension culture cell lines were transformed with the ARS-1 MAR-flanked GUS gene, they had 12-fold greater GUS expression when compared to the control transgenic lines with transgenes lacking MARs (Allen et al. 1996). When a plant MAR from the $R B 7$ gene was used, there was nearly 60-fold greater expression. An important result from both of these experiments was that transgene expression levels were not generally proportional to the transgene copy number. When the yeast MAR ARS-1 was used, expression appeared to be proportional to copy number until a "threshold" of 20 copies was reached (Allen et al. 1993) and transgene expression drastically decreased. The results were similar when the Rb7 MAR was used; lines with greater than ten copies (Allen et al. 1996) had greatly reduced expression. In contrast, when either the human $\beta$-globin MAR (Breyne et al. 1992) or the chicken lysozyme A-element MAR (Mlynarova et al. 1994) was used, a modest increase GUS expression was seen but the expression between transformants was less variable. In apparent contrast to the results of both groups, Schoffl et al. (1993) found that including flanking Gmhspl 7.6-L MARs resulted in expression levels that were both proportional to transgene copy number and five- to ninefold higher in expression following heat shock induction.

A comparison of the experimental designs used for each experiment reveals important differences. Allen et al. $(1993,1996)$ used microprojectile bombardment, a procedure that results in higher transgene copy numbers, and co-transformation, which in principle physically separates the reporter transgene from the selectable marker (see Sect. 3.1.1). Higher transgene copy numbers typically results in a higher probability of gene silencing. Allen et al. (1993, 1996) found that lines with genes lacking MARs showed much higher levels of silencing than the lines that contained MARs. The majority of the transformed lines that were studied also had multiple copies of 35S:GUS that were frequently at the same locus regardless of whether MARs were present or absent (Allen et al. 1993, 1996).

Studies during the past decade have generally concluded that the effect of flanking a transgene with MAR sequences is positive, although variation is still high. I have not included a detailed comparison of all of the MAR studies in plants

\footnotetext{
${ }^{4}$ Autonomously Replicating Sequence (ARS-1) from Saccharomyces is known to act as a SAR (MAR).
} 
because a comprehensive comparison of these experiments has been published elsewhere by Allen et al. (2000) and more recently by Thompson et al. (2006). In the following sections, I try to add some understanding for why such apparent variation can be explained by RNAi, which is not measured when transgene mRNA abundance or protein levels are used to assess the effect of MARs. Thus, if the RNAi-mediated reduction in transgene expression were to be taken into account an entirely different interpretation may result. Increasingly it is being recognized that MARs seem to prevent gene silencing in cis, but do not appear to be effective on gene silencing in trans. With this knowledge, new strategies are being developed that combine the use of MARs for preventing or reducing RNA-mediated cissilencing with new methods for reducing RNA-mediated trans-silencing.

\subsubsection{MARs Do Not Prevent Trans-Silencing: Transcriptional Silencing}

A simple interpretation of the loop domain model is that MARs protect a transgene from transcriptional gene silencing. However, these predictions need to be modified to explain the results from a series of experiments. As noted above, the original experiments using animal cell lines demonstrated that a transgene flanked by MARs is expressed at levels proportional to transgene copy number. However, Allen et al. (1993) and a subsequent study, which used animal cells (Poljak et al. 1994), demonstrated that lines with many transgene copies were not protected from silencing, even when MARs flanked the transgene.

The finding that MARs, at high copy number, do not prevent gene silencing supports a model in which homology-dependent gene silencing played a major role, especially when the transgene copy number was increased above a "threshold level." Vaucheret et al. (1998) crossed a variety of transgenic plants transformed by MAR-flanked transgenes with V271, a "super-silencer" plant that transcriptionally silences any "target" transgene that is driven by a CaMV 35S promoter (Vaucheret 1993). V271-mediated silencing occurred in trans, irrespective of the different target locations or the presence of MARs, suggesting that siRNAs corresponding to the $35 \mathrm{~S}$ promoter may have been actively recruiting transcriptional silencing machinery to the transgene loci.

Ascenzi et al. (2003) used a similar strategy and crossed lines with additional dominant (or trans-based) silencer loci with lines expressing "target" 35S transgene loci at various genomic locations (Ulker et al. 1999). In all of the crosses, the target loci were silenced, regardless of whether or not the Rb7 MAR flanked the target locus. Nuclear run-on assays, which test transcriptional activity, showed that two of the dominant silencer loci, with transgenes lacking MARs (control lines), appeared to be transcriptionally inactive, even though they were able to silence other $35 \mathrm{~S}$ genes in trans. Since siRNAs are needed to maintain heterochromatic areas at centromeres and other regions (Dunoyer et al. 2007; Howell et al. 2007; Kavi et al. 2005), which are not known to be transcribed at detectable levels, a similar mechanism may be in place for the dominant silencing loci. Perhaps during cell division siRNAs are transcribed to help re-establish heterochromatin after DNA replication. 
In a separate experiment, Ascenzi et al. crossed the F1 progeny of the dominant silencing line $\mathrm{x} 35 \mathrm{~S}$ gene (now silenced) line with a plant expressing $\mathrm{P} 1-\mathrm{HCPro}$, a viral suppressor of silencing. P1-HCPro is known to reverse RNA-silencing of transgenes (Anandalakshmi et al. 1998 and reviewed in Allen et al. 2000) and is thought to reverse Post-transcriptional Gene Silencing (PTGS) but not Transcriptional Gene Silencing (TGS). In the presence of P1-HCPro, silencing was eliminated in the $35 \mathrm{~S}$ target genes if they were flanked with MARs. In contrast, silencing could not be reversed in the lines transformed with transgenes lacking the MARs (control lines). These data provide strong evidence that MARs protect against transcriptional gene silencing, perhaps by impeding the formation of heterochromatin. Thus, when MAR-flanked transgenes are silenced, the silencing is likely due to RNAi that targets the transgene mRNA, or a portion of the promoter. In contrast a transgene that lacks MARs is susceptible to a different form of RNAi that is targeted to the transgene promoter (Park et al. 1996) and results in transcriptional silencing. Transgenes that are located in large DNA loops away from the matrix may be more accessible to heterochromatin machinery, and both the gene and the promoter may become silenced. In both cases, silencing requires the presence of RNA that is homologous to either the promoter or the transcribed region. One possibility for the difference in silencing response is that MARs may have prevented RNA polymerase read-through into the promoters of adjacent genes (reviewed in Allen et al. 2000 and in Thompson et al. 2006).

\subsubsection{MARs Do Not Prevent Trans-Silencing: Post-Transcriptional Silencing}

Such data lead to a predication that if MARs prevent a transgene from being transcriptionally silenced, then MAR-flanked transgenes could be expressed at a level that is copy-number dependent if RNAi that is targeted towards the highly expressed transgene mRNA is eliminated. Several Arabidopsis thaliana mutants have been found that are altered in the RNAi response (Dalmay et al. 2000; Elmayan et al. 1998). Butaye et al. (2004) transformed mutant A. thaliana $s g s 2^{5}$ and $s g s 3^{6}$ plants (Mourrain et al. 2000) with 35S:GUS transgenes either flanked, or not flanked by the chicken lysozyme A element MAR (Phi-Van et al. 1990; Stief et al. 1989). The MAR-flanked transgenes increased GUS expression by fivefold in $s g s 2$ and 12 -fold in sgs 3 plants. Transgene protein levels reached nearly $10 \%$ of the total soluble protein in some of the plants.

Butaye et al. (2005) also found that transgene expression in wild-type plants transformed with the MAR-flanked transgene was only $60 \%$ of the expression seen in plants transformed with the transgene lacking MARs. While the majority of studies in plants have reported a positive effect on transgene expression when MARs are included in the transgene (reviewed in Allen et al. 2000; and Thompson et al.

\footnotetext{
${ }^{5} \operatorname{sgs} 2$ is $r d r 6$ or RNA Dependent RNA Polymerase 6.

${ }^{6} \operatorname{sgs} 3$ is a plant- specific protein that is frequently associated with RNA-silencing.
} 
2006), an increase in transgene expression is not always seen. In fact, a decrease in transgene protein or mRNA would be expected if transcription rates drastically increased due to the flanking MARs and RNAi-mediated silencing was triggered. However, when RNAi cannot occur due to a mutation, the full stimulatory effect on expression due to the flanking MARs is revealed (Butaye et al. 2004).

In order for RNAi to occur, a target RNA must be present. However, if a gene is inducible or tissue/cell-specific, the target RNA may not be present at the same time or in the same cell as the silencing signal. If transcriptional activity causes silencing, then transgenes with inducible promoters, such as the tetracycline-inducible 3X promoter (Gatz et al. 1992), may be less susceptible to silencing. In order for RNAi to continue, the process must be actively maintained. To test this hypothesis, Abranches et al. (2005) used an inducible luciferase (LUC) reporter transgene with or without flanking Rb7 MARs. The $L U C$ transgene was transformed into NT1 tobacco suspension cells using microprojectile bombardment (Allen et al. 1996). The transformed lines were grown either under conditions for continuous transcription of $L U C$, or conditions where $L U C$ transcription was initially inactive but induced after approximately 50 cell generations ${ }^{7}$ (Gao et al. 1991). Delaying the induction resulted in an initial "burst" in LUC expression in the lines with the MAR-flanked $L U C$ transgene, which was then followed by a decrease in expression to levels that were similar to the levels seen in the lines with the continually transcribed 3X:LUC. Expression results from the continually expressed transgene were similar to earlier experiments when a 35S:GUS transgene was used. Regardless of transcriptional activity, expression of the $3 \mathrm{X}: L U C$ was higher in lines with MARflanking transgenes than in the lines with either a $\lambda$ DNA-flanked spacer control or the control lacking spacer DNA. These data confirmed that the process of transcription increases silencing, as previously noted (Baulcombe 1996; English and Baulcombe 1997; Que et al. 1997; Vaistij et al. 2002; van Blokland et al. 1997; Vaucheret et al. 1997), especially in the absence of the flanking Rb7 MAR. In addition, the MAR-flanked transgenes could be transcriptionally activated following prolonged inactivity, suggesting that MARs can prevent a transgene from being transcriptionally silenced by the spread of condensed chromatin or from siRNAs produced by readthrough from adjacent genes.

One of the original studies on the use of MARs in plants was by Schoffel et al. (1993), who demonstrated one of the clearest examples of position-independent transgene expression in plants with up to six transgene copies. Schoffl et al. (1993) also used Agrobacterium transformation and found a strong effect from a MAR from the soybean heat shock gene Gmhspl 7.6-L. With some exceptions, reports of strong MAR effects ( $\sim 3$-fold or greater) on plant transgene expression are less frequent when Agrobacterium transformation is used (Annadana et al. 2002; Breyne et al. 1992; Butaye et al. 2004; De Bolle et al. 2003; Halweg et al. 2005; HolmesDavis and Comai 2002; Kim et al. 2005; Levee et al. 1999; Maximova et al. 2003; Mlynarova et al. 1995, 1994, 2002; Oh et al. 2005; Sidorenko et al. 2003; Van der

\footnotetext{
${ }^{7} \mathrm{NT} 1$ generation time is approximately 17 hours.
} 
Geest et al. 1994; Van Leeuwen et al. 2001). In principle, use of induction following several rounds of cell division is similar to the approach used by Abranches et al. (2005). Schoffl et al. (1993) excised tobacco leaves, which were treated with a 2-h heat shock at $40^{\circ} \mathrm{C}$. In contrast to genes that are constantly being transcribed and therefore more susceptible to RNAi, the use of induction results in a transgene being transcribed in the absence of RNAi targeted towards the transgene. The flanking MARs act to prevent the spread of silencing through the transgene, thus keeping it poised for transcription following induction.

\subsubsection{MARs Prevent Cis-Silencing}

The model presented for how MARs improve transgene expression can best be described as minimizing gene silencing (reviewed by Allen et al. 2000). Until recently, the only data available for how MARs function has been circumstantial. For example, silencing can be reversed in lines that contain MARs flanking their transgene when crossed with plants expressing the viral suppressor of RNA VIGS, P1-HCPro (Anandalakshmi et al. 1998). In addition, MAR-flanked transgenes are expressed at a higher level than the same transgenes lacking MARs when transformed into A. thaliana with mutations in some of the key components of the RNAi pathway for sense-transgene silencing (Butaye et al. 2004). Additional data that support the model include findings that MARs do not protect against trans-silencing (Vaucheret et al. 1998) and that MAR-flanked transgenes are silenced when the transgene copy number reaches a threshold value (Allen et al. 1996; Allen et al. 1993). While these data are suggestive, they still only correlate MARs with protection against transgene silencing.

Conclusive data would require being able to examine a transgene with and without MARs at a defined position within the genome to avoid the possible variation due to differences in the chromatin structure at the site of integration. Regardless of how many transgenic lines are tested, it has not been possible to test MARs at specific locations in the genome due largely to the extremely low efficiency of gene targeting in higher plants (Britt and May 2003; Hanin and Paszkowski 2003; Kumar et al. 2006). However, it is possible to excise DNA with the use of site-specific recombination. Fiering et al. (1993) used the site-specific Flp recombinase that can excise DNA when the Flp Target Recognition (FRT) sites flank the DNA in direct repeats. This strategy allowed Fiering et al. (1993) to compare the effect of various regulatory regions from the $\beta$-globin Locus Control Region on the expression of a transgene. Initially, the transgene and regulatory region flanked by FRT was transformed into the genome. The transgene expression levels and other characteristics, such as DNase I sensitivity, can then be tested. The Flp recombinase is then expressed in the cell by transient expression, to excise the particular regulatory element being tested. Transgene expression and the other characteristics can then again be analyzed at the same location. The difference in expression can then be directly attributed to the presence or absence of the regulatory element. 
Mlynarova et al. (2003) transformed tobacco with a 35S:GUS reporter gene with the chicken lysozyme A element MAR. The MARs flanked both the 35S:GUS reporter and the selection gene, nos promoter:nptII. One flanking MAR was flanked by the wild-type loxP and the second MAR was flanked by a mutated form of $\operatorname{lox} P$ (lox511). In principle the wild-type loxP can only recombine with wild-type loxP and the lox511 can only recombine with lox511. In the presence of Cre recombinase, which had been introduced by re-transformation with $35 \mathrm{~S}: \mathrm{Cre}$, either loxP or lox511 self-recombination would result in the excision of the specific MAR flanking each transgene, GUS and nptII. It was anticipated that the resulting progeny would be missing a MAR from either flank of the reporter gene-selection gene domain. In many of the progeny the mutated lox511 and wild-type loxP had recombined, however, it was possible to find one progeny line was missing a single MAR, line AGCNA-61 (see Fig. 3).

A comparison of the AGCNA-61 GUS expression showed that when the 3' MAR was present $G U S$ expression was retained throughout the life of the plant. However, AGCNA-61 plants in which the MAR had been excised showed several characteristics that are typically found in plants silenced by RNAi. For example, a comparison of GUS expression at different times showed that after 3 months the AGCNA-61 plants lacking the MAR showed a strong loss in GUS activity, and the silencing was intensified in homozygous plants. Nuclear run-on assays confirmed that the 35S:GUS transgene in AGCNA-61 plants remained transcriptionally active even when
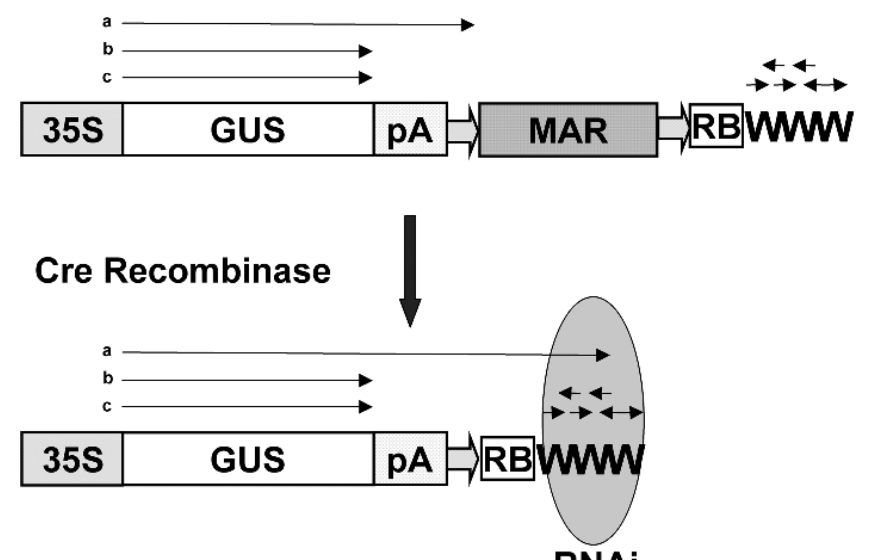

Fig. 3 MARs prevent readthrough transcription and Cis silencing. (Top) The 35S:GUS transgene with a nos polyadenylation signal (pA). Transcripts are produced as shown by arrows $\mathbf{a}, \mathbf{b}$, and $\mathbf{c}$. The A element chicken lysozyme MAR at the $3^{\prime}$ end of the transgene cassette blocks readthrough transcript a from continuing into the highly condensed plant DNA $(\mathbf{W})$ flanking the transgene. The mutant loxP511 sites (wide arrows) are organized as direct repeats to flank the MAR. (Bottom) In the presence of Cre recombinase the directly repeated loxP511 sites recombine and the MAR is excised from the genome. Transcript a readthrough continues into the highly condensed plant flanking DNA. Small RNAs (small arrows) produced within the flanking DNA form doublestranded RNA with homology to readthrough the $3^{\prime}$ end of transcript a and RNAi (grey oval) is initiated, which spreads into and silences the 35S:GUS transgene 
the MAR was absent. When the same plants were tested by Real Time-Polymerase Chain Reaction (RT-PCR), the AGCNA-61 plants lacking the MAR had a greatly reduced level of GUS mRNA. Importantly, when the same plants were compared for the presence of siRNAs for $G U S$, only the AGCNA-61 plants lacking the MAR showed 21-24-bp RNAs. The presence of the 21-24-bp RNAs is found in plants that have active RNAi (Hamilton and Baulcombe 1999; Hamilton et al. 2002), which in this case was targeted against the GUS mRNA. This finding supports the hypothesis that MARs protect transgenes from $c$ is-silencing by RNAi. As noted earlier, RNAi has been shown to be key for the initiation and maintenance of heterochromatin.

\subsubsection{Agrobacterium Transformation and Selection Bias}

As noted in the previous section, one reason why MARs appear to improve transgene expression from some gene cassettes used for transformation but have no effect in others may be explained by the different types of gene silencing that MARs prevent. However, differences in the method of transformation may also play an important role. The greatest increases in transgene expression seen in experiments have resulted from transformants produced by direct DNA transformation, such as microprojectile bombardment. It is generally thought that the use of direct DNA transformation results in a higher transgene copy number than when Agrobacterium transformation is used. It is well known that higher transgene copy numbers have an increased probability of being silenced, or have greater expression variation (Hobbs et al. 1990, 1993; Koprek et al. 2001).

The use of direct DNA transformation does have an important advantage for studying the effect of MARs on transgene expression because the selectable marker transgene and the reporter transgene can be physically separated and a co-transformation procedure can be used in which the separate marker and the reporter genes are mixed prior to transformation. By unlinking the selection and the reporter genes, the transformation process for each is independent, and there is no selection bias for strong or against weak gene expression. In practice, transformants are first identified by resistance to the selective agent and then are measured for reporter gene activity. By physically unlinking the selection and the reporter gene, integration of the reporter gene can occur into different genomic locations and still be recovered so that possible differences in transgene copy number are meaningful.

While co-transformation can also be done using Agrobacterium (Komari et al. 1996; De Neve et al. 1997; Iradani 1998; Vain et al. 2003), all of the MAR studies to date have been done using binary vectors with the selection and reporter transgenes physically linked (reviewed in Allen et al. 2000; and Thompson et al. 2006). A typical Agrobacterium transformation involves infection of the competent plant tissue, killing of the Agrobacterium, and selecting for cells that can survive the antibiotic or herbicide due to the presence of the selection transgene. It is critical that the selectable marker transgene be expressed in order for the cells to survive and proliferate. Cells that are "transformed" but do not express the selectable marker are routinely discarded. The use of selection therefore creates a bias by 
selecting only for transformants with active transgenes which must be integrated into regions of the genome that are transcriptionally active at the time of selection, such as euchromatin. Of course, the linked reporter transgene integrates into the same active genomic region and thus the integration sites cannot be random.

According to the loop domain model, the importance of flanking MARs becomes most evident when a transgene integrates into inactive, condensed regions of the genome, such as heterochromatin. If a method of identifying transformed cells that does not rely on selection is used it then becomes possible to achieve more random integration. A recent study by Francis and Spiker (2005) demonstrated how selection bias may impact our interpretation by using a PCR method to identify transgenic plants with integrated nptII selection and GUS reporter genes. When transformants that had been identified by PCR were tested for kanamycin resistance, which requires nptII expression, approximately $30 \%$ were sensitive indicating that the selection and linked reporter gene had integrated into a region of the genome that was prone to gene silencing. These results were confirmed recently by Kim et al. (2007) who transformed A. thaliana Col-0 suspension cells in the absence of selection. Transformants were identified with T-DNA integration events that had a higher probability of occurring in heterochromatic regions, such as centromeres, telomeres, and rDNA repeat regions.

\subsubsection{Do MARs Impact Transgene Integration Events?}

Selection requires active expression of the selection gene. When selection is used, transgene integration is highly likely to occur in transcriptionally poised or active genomic regions. If MARs are associated with regions of active transcription, would a higher percentage of the selection-derived transformants integrate in close proximity to endogenous MARs, especially when the transgene construct used lacks flanking MARs? Second, if transformants could be identified without the use of selection, would such transgenes be found in genomic regions lacking local endogenous MARs? Of course, for truly random integration to occur, it would be necessary to assume that the endogenous MARs do not enhance integration site preference. Interestingly, several studies have found either predicted (Makarevitch et al. 2003), or experimentally tested MARs (Dietz et al. 1994; Iglesias et al. 1997; Sawasaki et al. 1998; Takano et al. 1997) in close proximity to the site of transgene integration, but selection has typically been used to identify these transformants. The interpretation from such results is that transgenes integrate near endogenous MARs, but to truly address these questions, it is necessary to study integration sites from transformants identified without selection bias.

Koprek et al. (2001) described a novel approach that may provide some of the answers to this question. The Agrobacterium transformation included a selection step to identify the primary transformants with the transgene integrated at the "launchpad" integration site. However, an AC/DS transposon system was then used to generate novel genomic integration sites, resulting from transposition, without using selection. This procedure allows the DS element, carrying a Bar gene (Basta 
resistance), to randomly integrate into new genomic positions during the transposition process. Initially the Bar transgene, flanked by inverted-repeat DS ends (Bar-DS), was transformed into barley using Agrobacterium and transformants were selected on the herbicide Basta. The Basta-resistant transformants were then crossed with a plant expressing the $\mathrm{AC}$ transposase gene and the $\mathrm{F}_{1}$ progeny were then self-pollinated. The $\mathrm{F}_{2}$ plants were then re-tested for Basta resistance. When transposition occurred, $25 \%$ of the new integration sites were unlinked from the original site, indicating that Bar had integrated into different chromosomes.

A subsequent study by Zhao et al. (2006) mapped the initial Bar-DS integration sites and the new integration sites following transposition. Sequence analysis of the initial T-DNA integration sites, which were selected for by Basta, found a sevenfold greater preference for integration into non-redundant, gene-rich regions of the barley genome versus non-gene regions. In contrast, when the new sites resulting from DS elements were mapped, a preference for regions containing endogenous MARs was found. It is possible that the DS transposon prefers more accessible chromatin with MARs, or that regions containing MARs are generally favored sites for the integration of new DNA. This could occur, for example, if DNA repair enzymes were more likely to be found in active parts of the genome.

Petersen et al. (2002) transformed barley with 35S:GUS transgenes flanked by either the P1 MAR from soybean (Breyne et al. 1992) or the Transformation Booster Sequence (TBS) MAR from petunia (Buising and Benbow 1994; Galliano et al. 1995; Meyer et al. 1988). In vitro MAR binding assays using nuclear matrix isolated from barley leaves showed that the P1 MAR bound strongly whereas the TBS MAR binding was insignificant. Interestingly, both MARs increased the transformation efficiency by approximately twofold, but only the P1 MAR increased expression (12- to 13-fold). The mechanism for how both the P1MAR and the TBS MAR stimulate transformation is unknown but not completely unexpected. Because, as Zhao et al. (2006) noted, though DS elements integrate preferentially near endogenous MARs, the converse may also be true: MARs that are associated with transgenes may facilitate integration.

\section{The Use of MARs to Improve the Stability of Transgene Expression}

\subsection{MARs for Protein Overexpression}

Much of the research on MARs has focused on their practical use as tools for preventing the cis-silencing of transgenes. MARs can be used in combination with other strategies such as plants with mutations in silencing components (Butaye et al. 2004) or plants transformed with viral suppressors of silencing (Anandalakshmi et al. 1998; Marathe et al. 2000) that block, in trans, RNA silencing and achieve high levels of transgene expression. Several examples have been published that 
have used MARs in combination with a gene of interest for practical applications such as reducing photorespiration to improve photosynthesis and biomass production (Kebeish et al. 2007; Khan 2007; Leegood 2007; Niessen et al. 2007), increasing expression of a starch-branching enzyme (Kim et al. 2005), or increasing stilbene synthase expression (Jin et al. 2004). While MARs can be used for increasing the level of expression of a useful gene product, very high expression levels may also show an increased likelihood of initiating RNA silencing. It is highly likely that reports from various labs in which MARs have little or even negative effects in certain transformation experiments are due to post-transcriptional gene silencing (Baulcombe 1999).

\subsection{MARs for Stabilizing RNAi}

Ironically, according to the model, including MARs in a transgene construct may be one of the best ways to stabilize trans-silencing through post-transcriptional gene silencing, or RNAi. Gene knockdown through RNAi is increasingly becoming important as a method for understanding gene function (McGinnis et al. 2007; Waterhouse and Helliwell 2003) and for metabolic pathway engineering (Chen et al. 2005; Kotting et al. 2005; Kusaba 2004; Tang and Galili 2004). Many recent applications use RNAi constructs to knockdown the expression of an endogenous gene through the use of hairpin constructs (Waterhouse and Helliwell 2003). In order for RNAi to continue to function it is necessary for the hairpin construct to continue to be transcriptionally active. In some cases the RNAi vector becomes transcriptionally silenced, leading to loss of the knockdown phenotype (Fojtova et al. 2003; Kerschen et al. 2004). MARs work well for preventing cis-silencing of the promoter and have been shown to stabilize the transcriptional activity of cassettes containing viral genes for silencing incoming viral sequences vectors for producing virus-resistant plants (Robertson 2004).

One specific example of the benefit of using MARs to stabilize silencing comes from work in tobacco, testing resistance to the tospovirus Tomato Spotted Wilt Virus (TSWV) (Levin et al. 2005). A transgene cassette designed for constitutive expression of the TSWV 35S: nucleocapsid protein gene, TSWV-N with and without flanking Rb7 MARs was used to transform tobacco. When a total of 79 MAR and 66 non-MAR events were tested in the field over four generations, the MARcontaining plants showed significantly higher levels of resistance to TSWV, which is transmitted throughout the field season by thrips. These findings validate the prediction that PTGS plays an active role in the final expression levels of MARflanked genes and that before concluding that MARs themselves have a negative effect on gene expression, silencing must be tested or eliminated as a variable. Levin et al. (2005) showed that resistant lines produced small RNAs of 21-25 bp and that they maintained transcriptional activity as demonstrated by nuclear run-on assays. The Levin et al. experiment clearly demonstrates the value of MARs for preserving transcriptional activity and maintaining virus resistance. 


\section{Conclusion}

Much of our current understanding of the role MARs play in higher-order chromatin structure and nuclear architecture comes from research with yeast and animal cells, while the research on MARs in plants has been primarily limited to whether including MARs in transgene constructs can be used as a tool to stabilize transgene expression. While understanding whether MARs improve transgene expression is important, MARs are also thought to be important for other basic nuclear processes such as DNA replication and nuclear organization. New research shows that the non-coding regions of the genome that were previously called "junk DNA" are critical for controlling the expression of genes.

Genome sequencing has enabled researchers to begin to see how genes and noncoding regions are organized and to begin to make predictions based on similarity. However, much work remains to be done in order to understand how the sequences are arranged in a three-dimensional space. A computer algorithm has been developed to predict MARs (Rudd et al. 2004; Tetko et al. 2006) and it has been used to predict the MARs in the Arabidopsis thaliana genome. However, when the algorithm was used to predict known plant MARs only $60 \%$ were "found." In contrast, an earlier algorithm, called MAR-finder (Singh et al. 1997) was able to predict nearly $80 \%$ of the known plant MARs. A major limitation for both algorithms is the lack of experimental data. New genomic approaches that allow the identification and mapping of large numbers of sequences that bind to the matrix may eventually provide such data (Linnemann et al. 2007).

Finally, the field of nuclear organization and the nuclear matrix remains controversial and much of the controversy is fueled by our lack of knowledge about the nuclear matrix and whether it even exists as a discrete entity (Pederson 2000). New tools are desperately needed to compare the properties of the nuclear matrix in different tissues, over time, and as the nucleus changes shape and/or undergoes endoreduplication. What is the role of nuclear actin? What role does RNA play in the nuclear matrix? How are MARs recognized, and what is the biological significance of MARs with different binding affinities? New methods will be needed to examine large-scale protein-protein interactions in living cells, and to begin to unravel the role of RNA both as a catalyst and as a structural component (Rozowsky et al. 2007; Washietl et al. 2007). With the current rate of advances in technology and information processing, the future for understanding how basic units of genetic information are maintained in three-dimensional space, over time, and how their structure relates to function, is very promising.

\section{References}

Abranches R, Shultz RW, Thompson WF, Allen GC (2005) Matrix attachment regions and regulated transcription increase and stabilize transgene expression. Plant Biotech J 3:535-543 
Aguilera A (2005) Cotranscriptional mRNP assembly: from the DNA to the nuclear pore. Curr Opin in Cell Biol 17:242-250

Alberts B, Johnson A, Lewis J, Raff M, Roberts K, Walter P (2002) Molecular biology of the cell. Garland, New York

Alberts B, Sternglanz R (1990) Chromatin contract to silence. Nature 344:193-194

Allen GC, Hall G, Michalowski S, Newman W, Spiker S, Weissinger AK, Thompson WF (1996) High-level transgene expression in plant cells: effects of a strong scaffold attachment region from tobacco. Plant Cell 8:899-913

Allen GC, Hall GE Jr, Childs LC, Weissinger AK, Spiker S, Thompson WF (1993) Scaffold attachment regions increase reporter gene expression in stably transformed plant cells. Plant Cell 5:605-613

Allen GC, Spiker S, Thompson WF (2000) Use of matrix attachment regions (MARs) to minimize transgene silencing. Plant Mol Biol 43:361-376

Allen ND, Cran DG, Barton SC, Hettle S, Reik W, Surani MA (1988) Transgenes as probes for active chromosomal domains in mouse development. Nature 333:852-855

Amati BB, Gasser SM (1988) Chromosomal ARS and CEN elements bind specifically to yeast nuclear scaffold. Cell 54:967-978

Anandalakshmi R, Pruss GJ, Ge X, Marathe R, Mallory AC, Smith TH, Vance VB (1998) A viral suppressor of gene silencing in plants. Proc Natl Acad Sci USA 95:13079-13084

Annadana S, Mlynarova L, Udayakumar M, de Jong J, Nap JP (2002) The potato Lhca3.St.1 promoter confers high and stable transgene expression in chrysanthemum, in contrast to CaMV-based promoters. Mol Breed 8:335-344

Ascenzi R, Ulker B, Todd JJ, Sowinski DA, Schimeneck CR, Allen GC, Weissinger AK, Thompson WF (2003) Analysis of trans-silencing interactions using transcriptional silencers of varying strength and targets with and without flanking nuclear matrix attachment regions. Trans Res 12:305-318

Assaad FF, Tucker KL, Signer ER (1993) Epigenetic repeat-induced silencing (RIGS) in Arabidopsis. Plant Mol Biol 22:1067-1085

Baulcombe DC (1996) RNA as a target and an initiator of post-transcriptional gene silencing in transgenic plants. Plant Mol Biol 32:79-88

Baulcombe DC (1999) Gene silencing: RNA makes RNA makes no protein. Curr Biol 9:R599-R601

Berezney R, Coffey DS (1974) Identification of a nuclear protein matrix. Biochem Biophys Res Commun 60:1410-1417

Bi X, Yu Q, Sandmeier JJ, Zou Y (2004) Formation of boundaries of transcriptionally silent chromatin by nucleosome-excluding structures. Mol Cell Biol 24:2118-2131

Bode J, Maass K (1988) Chromatin domain surrounding the human interferon-b gene as defined by scaffold-attached regions. Biochem 27:4706-4711

Bodnar JW (1988) A domain model for eukaryotic DNA organization: a molecular basis for cell differentiation and chromosome evolution. J Theor Biol 132:479-507

Bonifer C, Hecht A, Saueressig H, Winter DM, Sippel AE (1991) Dynamic chromatin: the regulatory domain organization of eukaryotic gene loci. J Cell Biochem 47:99-108

Bourdon V, Ladbrooke Z, Wickham A, Lonsdale D, Harwood W (2002) Homozygous transgenic wheat plants with increased luciferase activity do not maintain their high level of expression in the next generation. Plant Sci 163:297-305

Bregitzer P, Tonks D (2003) Inheritance and expression of transgenes in barley. Crop Sci 43:4-12

Breyne P, van Montagu M, Depicker A, Gheysen G (1992) Characterization of a plant scaffold attachment region in a DNA fragment that normalizes transgene expression in tobacco. Plant Cell 4:463-471

Brickner DG, Cajigas I, Fondufe-Mittendorf Y, Ahmed S, Lee P-C, Widom J, Brickner JH (2007) H2A.Z-mediated localization of genes at the nuclear periphery confers epigenetic memory of previous transcriptional state. PLoS Biol 5:e81

Britt AB, May GD (2003) Re-engineering plant gene targeting. Trends Plant Sci 8:90-95 
Buising CM, Benbow RM (1994) Molecular analysis of transgenic plants generated by microprojectile bombardment - effect of petunia transformation booster sequence. Mol Gen Genet 243:71-81

Butaye KMJ, Goderis IJWM, Wouters PFJ, Pues JM-TG, Delaure SL, Broekaert WF, Depicker A, Cammue BPA, De Bolle MFC (2004) Stable high-level transgene expression in Arabidopsis thaliana using gene silencing mutants and matrix attachment regions. Plant $\mathrm{J}$ 39:440-449

Butaye KMJ, Cammue BPA, Delaure, SL, De Bolle MFC (2005) Approaches to minimize variation of transgene expression in plants. Mol Breeding 16:79-81

Cabal GG, Genovesio A, Rodriguez-Navarro S, Zimmer C, Gadal O, Lesne A, Buc H, FeuerbachFournier F, Olivo-Marin J-C, Hurt EC, Nehrbass U (2006) SAGA interacting factors confine sub-diffusion of transcribed genes to the nuclear envelope. Nature 441:770-773

Callard D, Mazzolini L (1997) Identification of proliferation-induced genes in Arabidopsis thaliana. Characterization of a new member of the highly evolutionarily conserved histone H2A.F/Z variant subfamily. Plant Physiol 115:1385-1395

Casolari JM, Brown CR, Komili S, West J, Hieronymus H, Silver PA (2004) Genome-wide localization of the nuclear transport machinery couples transcriptional status and nuclear organization. Cell 117:427-439

Chareonpornwattana S, Thara KV, Wang L, Datta SK, Panbangred W, Muthukrishnan S (1999) Inheritance, expression, and silencing of a chitinase transgene in rice. Theor Appl Genet 98:371-378

Chen S, Hajirezaei M, Peisker M, Tschiersch H, Sonnewald U, Bornke F (2005) Decreased sucrose-6-phosphate phosphatase level in transgenic tobacco inhibits photosynthesis, alters carbohydrate partitioning, and reduces growth. Planta 221:479-492

Choi K, Park C, Lee J, Oh M, Noh B, Lee I (2007) Arabidopsis homologs of components of the SWR1 complex regulate flowering and plant development. Develop 134:1931-1941

Chua YL, Brown AP, Gray JC (2001) Targeted histone acetylation and altered nuclease accessibility over short regions of the pea plastocyanin gene. Plant Cell 13:599-612

Chua YL, Watson LA, Gray JC (2003) The transcriptional enhancer of the pea plastocyanin gene associates with the nuclear matrix and regulates gene expression through histone acetylation. Plant Cell 15:1468-1479

Cockerill PN, Garrard WT (1986) Chromosomal loop anchorage of the kappa immunoglobulin gene occurs next to the enhancer in a region containing topoisomerase II sites. Cell 44:273-282

Cole CN, Scarcelli JJ (2006) Transport of messenger RNA from the nucleus to the cytoplasm. Curr Opin Cell Biol 18:299-306

Cook PR (1989) The nucleoskeleton and the topology of transcription. Eur J Biochem 185:487-501

Crawford GE, Davis S, Scacheri PC, Renaud G, Halawi MJ, Erdos MR, Green R, Meltzer PS, Wolfsberg TG, Collins FS (2006) DNase-chip: a high-resolution method to identify DNase I hypersensitive sites using tiled microarrays. Nat Methods 3:503-509

Cuvier O, Hart CM, Kas E, Laemmli UK (2002) Identification of a multicopy chromatin boundary element at the borders of silenced chromosomal domains. Chromosoma 110:519-531

Dalmay T, Hamilton A, Rudd S, Angell S, Baulcombe DC (2000) An RNA-dependent RNA polymerase gene in Arabidopsis is required for posttranscriptional gene silencing mediated by a transgene but not by a virus. Cell 101:543-553

De Bolle MFC, Butaye KMJ, Coucke WJW, Goderis I, Wouters PFJ, van Boxel N, Broekaert WF, Cammue BPA (2003) Analysis of the influence of promoter elements and a matrix attachment region on the inter-individual variation of transgene expression in populations of Arabidopsis thaliana. Plant Sci 165:169-179

De Neve M, De Buck S, De Wilde C, Van Houdt H, Strobbe I, Jacobs A, Van M, Depicker A (1997) T-DNA integration patterns in co-transformed plant cells suggest that T-DNA repeats originate from co-integration of separate T-DNAs. Plant J 11:15-29 
De Neve M, De Buck S, De Wilde C, Van Houdt H, Strobbe I, Jacobs A, Van M, Depicker A (1999) Gene silencing results in instability of antibody production in transgenic plants. Mol Gen Genet 260:582-592

Deal RB, Kandasamy MK, McKinney EC, Meagher RB (2005) The nuclear actin-related protein ARP6 is a pleiotropic developmental regulator required for the maintenance of FLOWERING LOCUS C expression and repression of flowering in Arabidopsis. Plant Cell 17:2633-2646

Deal RB, Topp CN, McKinney EC, Meagher RB (2007) Repression of flowering in Arabidopsis requires activation of FLOWERING LOCUS C expression by the histone variant H2A.Z. Plant Cell 19:74-83

Dean C, Jones J, Favreau M, Dunsmuir P, Bedbrook J (1988) Influence of flanking sequences on variability in expression levels of an introduced gene in transgenic tobacco plants. Nucleic Acids Res 16:9267-9283

Dietz A, Kay V, Schlake T, Landsmann J, Bode J (1994) A plant scaffold attacked region detected close to a T-DNA integration site is active in mammalian cells. Nucleic Acids Res 22:2744-2751

Dilworth DJ, Tackett AJ, Rogers RS, Yi EC, Christmas RH, Smith JJ, Siegel AF, Chait BT, Wozniak RW, Aitchison JD (2005) The mobile nucleoporin Nup2p and chromatin-bound Prp20p function in endogenous NPC-mediated transcriptional control. J Cell Biol 171:955-965

Dorer DR, Henikoff S (1997) Transgene repeat arrays interact with distant heterochromatin and cause silencing in cis and trans. Genetics 147:1181-1190

Dunoyer P, Himber C, Ruiz-Ferrer V, Alioua A, Voinnet O (2007) Intra- and intercellular RNA interference in Arabidopsis thaliana requires components of the microRNA and heterochromatic silencing pathways. Nat Genet 39:848-856

Elmayan T, Balzergue S, Beon F, Bourdon V, Daubremet J, Guenet Y, Mourrain P, Palauqui JC, Vernhettes S, Vialle T, Wostrikoff K, Vaucheret H (1998) Arabidopsis mutants impaired in cosuppression. Plant Cell 10:1747-1757

English JJ, Baulcombe DC (1997) The influence of small changes in transgene transcription on homology-dependent virus resistance and gene silencing. Plant J 12:1311-1318

Fiering S, Kim C, Epner E, Groudine M (1993) An "in-out" strategy using gene targeting and FLP recombinase for the functional dissection of complex DNA regulatory elements: analysis of the $\beta$-globin locus control region. Proc Natl Acad Sci USA 90:8469-8473

Fojtova M, Van Houdt H, Depicker A, Kovarik A (2003) Epigenetic switch from posttranscriptional to transcriptional silencing is correlated with promoter hypermethylation. Plant Physiol 133:1240-1250

Francis KE, Spiker S (2005) Identification of Arabidopsis thaliana transformants without selection reveals a high occurrence of silenced T-DNA integrations. Plant J 41:464-477

Galliano H, Muller AE, Lucht JM, Meyer P (1995) The transformation boaster sequence from Petunia hybrida is a retrotransposon derivative that binds to the nuclear scaffold. Mol Gen Genet 247:614-622

Gao J, Lee JM, An G (1991) The stability of foreign protein production in genetically modified plant cells. Plant Cell Rep 10:533-536

Gasser SM, Laemmli UK (1986) The organization of chromatin loops: characterization of a scaffold attachment site. EMBO J 5:511-518

Gaszner M, Felsenfeld G (2006) Insulators: exploiting transcriptional and epigenetic mechanisms. Nat Rev Genet 7:703-713

Gatz C, Claus F, Regina W (1992) Stringent repression and homogeneous de-repression by tetracycline of a modified CaMV 35S promoter in intact transgenic tobacco plants. Plant J 2:397-404

Gendrel AV, Lippman Z, Martienssen R, Colot V (2005) Profiling histone modification patterns in plants using genomic tiling microarrays. Nat Methods 2:213-218

Gendrel AV, Lippman Z, Yordan C, Colot V, Martienssen RA (2002) Dependence of heterochromatic histone $\mathrm{H} 3$ methylation patterns on the Arabidopsis gene DDM1. Science 297:1871-1873 
Gepts P (2002) A comparison between crop domestication, classical plant breeding, and genetic engineering. Crop Sci 42:1780-1790

Giresi PG, Lieb JD (2006) How to find an opening (or lots of them). Nat Methods 3:501-502

Goetze S, Baer A, Winkelmann S, Nehlsen K, Seibler J, Maass K, Bode J (2005) Performance of genomic bordering elements at predefined genomic loci. Mol Cell Biol 25:2260-2272

Greally JM (2007) Genomics: encyclopaedia of humble DNA. Nature 447:782-783

Greb T, Mylne JS, Crevillen P, Geraldo N, An H, Gendall AR, Dean C (2007) The PHD finger protein VRN5 functions in the epigenetic silencing of Arabidopsis FLC. Curr Biol 17:73-78

Gromova II, Nielsen OF, Razin SV (1995) Long-range fragmentation of the eukaryotic genome by exogenous and endogenous nucleases proceeds in a specific fashion via preferential DNA cleavage at matrix attachment sites. J Biol Chem 270:18685-18690

Grosveld F, van Assendelft GB, Greaves DR, Kollias G (1987) Position-independent, high-level expression of the human b-globin gene in transgenic mice. Cell 51:975-985

Hall GE, Jr., Allen GC, Loer DS, Thompson WF, Spiker S (1991) Nuclear scaffolds and scaffoldattachment regions in higher plants. Proc Natl Acad Sci USA 88:9320-9324

Hall IM, Shankaranarayana GD, Noma K, Ayoub N, Cohen A, Grewal SI (2002) Establishment and maintenance of a heterochromatin domain. Science 297:2232-2237

Halweg C, Thompson WF, Spiker S (2005) The Rb7 matrix attachment region increases the likelihood and magnitude of transgene expression in tobacco cells: a flow cytometric study. Plant Cell 17:418-429

Hamilton A, Voinnet O, Chappell L, Baulcombe D (2002) Two classes of short interfering RNA in RNA silencing. EMBO J 21:4671-4679

Hamilton AJ, Baulcombe DC (1999) A species of small antisense RNA in post transcriptional gene silencing in plants. Science 286:950-952

Hanin M, Paszkowski J (2003) Plant genome modification by homologous recombination. Curr Opin Plant Biol 6:157-162

Henderson IR, Jacobsen SE (2007) Epigenetic inheritance in plants. Nature 447:418-424

Heng HH, Goetze S, Ye CJ, Liu G, Stevens JB, Bremer SW, Wykes SM, Bode J, Krawetz SA (2004) Chromatin loops are selectively anchored using scaffold/matrix-attachment regions. J Cell Sci 117:999-1008

Henikoff S (1998) Conspiracy of silence among repeated transgenes. Bioessays 20:532-535

Hobbs SLA, Kpodar P, Delong CMO (1990) The effect of T-DNA copy number, position and methylation on reporter gene expression in tobacco transformants. Plant Mol Biol 15:851-864

Hobbs SLA, Warkentin TD, DeLong CMO (1993) Transgene copy number can be positively or negatively associated with transgene expression. Plant Mol Biol 21:17-26

Holmes-Davis R, Comai L (2002) The matrix attachment regions (MARs) associated with the heat shock cognate 80 gene (HSC 80 ) of tomato represent specific regulatory elements. Mol Gen Gen 266:891-898

Howell MD, Fahlgren N, Chapman EJ, Cumbie JS, Sullivan CM, Givan SA, Kasschau KD, Carrington JC (2007) Genome-wide analysis of the RNA-DEPENDENT RNA POLYMERASE6/ DICER-LIKE4 pathway in Arabidopsis reveals dependency on miRNA- and tasiRNA-directed targeting. Plant Cell 19:926-942

Iglesias VA, Moscone EA, Papp I, Neuhuber F, Michalowski S, Phelan T, Spiker S, Matzke M, Matzke AJM (1997) Molecular and cytogenetic analyses of stably and unstably expressed transgene loci in tobacco. Plant Cell 9:1251-1264

Iradani T, Bogani P, Mengoni A, Mastromei G, Buiatti M (1998) Construction of a new vector conferring methotrexate resistance in Nicotiana tabacum plants. Plant Mol Biol 37:1079-1084

Ishii K, Arib G, Lin C, Van Houwe G, Laemmli UK (2002) Chromatin boundaries in budding yeast: the nuclear pore connection. Cell 109:551-562

Istomina NE, Shushanov SS, Springhetti EM, Karpov VL, Krasheninnikov IA, Stevens K, Zaret KS, Singh PB, Grigoryev SA (2003) Insulation of the chicken b-globin chromosomal domain from a chromatin-condensing protein, MENT. Mol Cell Biol 23:6455-6468 
Jacobsen SE (1999) Gene silencing: maintaining methylation patterns. Curr Biol 9:R617-R619

James VA, Worland B, Snape JW, Vain P (2004) Strategies for precise quantification of transgene expression levels over several generations in rice. J Exp Bot 55:1307-1313

Jin C, Felsenfeld G (2007) Nucleosome stability mediated by histone variants H3.3 and H2A.Z. Genes Dev 21:1519-1529

Jin Z, Shu-Jun L, Si-Song M, Wei Y, Yuan-Lei H, Qiang W, Zhong-Ping L (2004) Effect of Matrix Attachment Regions on resveratrol production in tobacco with transgene of stilbene synthase from Parthenocissus henryana. Acta Bot Sin 46:948-954

Johnson L, Cao X, Jacobsen S (2002) Interplay between two epigenetic marks. DNA methylation and histone $\mathrm{H} 3$ lysine 9 methylation. Curr Biol 12:1360-1367

Jorgensen RA, Cluster PD, English J, Que QD, Napoli CA (1996) Chalcone synthase cosuppression phenotypes in petunia flowers: comparison of sense vs. antisense constructs and singlecopy vs. complex T-DNA sequences. Plant Mol Biol 31:957-973

Kamakaka RT, Biggins S (2005) Histone variants: deviants? Genes Dev 19:295-310

Kavi HH, Xie W, Fernandez HR, Birchler JA (2005) Global analysis of siRNA-mediated transcriptional gene silencing. Bioessays 27:1209-1212

Kebeish R, Niessen M, Thiruveedhi K, Bari R, Hirsch H-J, Rosenkranz R, Stabler N, Schonfeld B, Kreuzaler F, Peterhansel C (2007) Chloroplastic photorespiratory bypass increases photosynthesis and biomass production in Arabidopsis thaliana. Nat Biotech 25:593-599

Kerschen A, Napoli CA, Jorgensen RA, Muller AE (2004) Effectiveness of RNA interference in transgenic plants. FEBS Lett 566:223-228

Khan MS (2007) Engineering photorespiration in chloroplasts: a novel strategy for increasing biomass production. Trends Biotech 25:437-440

Kim S-I, Veena, Gelvin SB (2007) Genome-wide analysis of Agrobacterium T-DNA integration sites in the Arabidopsis genome generated under non-selective conditions. Plant $\mathbf{J}$ 51:779-791

Kim WS, Kim J, Krishnan HB, Nahm BH (2005) Expression of Escherichia coli branching enzyme in caryopses of transgenic rice results in amylopectin with an increased degree of branching. Planta 220:689-695

Kodama Y, Nagaya S, Shinmyo A, Kato K (2007) Mapping and characterization of DNase I hypersensitive sites in Arabidopsis chromatin. Plant Cell Physiol 48:459-470

Komari T, Hiei T, Saito Y, Murai N, Kumashiro T (1996) Vectors carrying two separate T-DNAs for co-transformation of higher plants mediated by Agrobacterium tumefaciens and segregation of transformants free from selection markers. Plant J 10:165-174

Koprek T, Rangel S, McElroy D, Louwerse JD, Williams-Carrier RE, Lemaux PG (2001) Transposon-mediated single-copy gene delivery leads to increased transgene expression stability in barley. Plant Physiol 125:1354-1362

Kotting O, Pusch K, Tiessen A, Geigenberger P, Steup M, Ritte G (2005) Identification of a novel enzyme required for starch metabolism in Arabidopsis leaves. The phosphoglucan, water dikinase. Plant Physiol 137:242-252

Kumar S, Franco M, Allen GC (2006) Gene targeting: development of novel systems for genome engineering in plants. In: Teixeira da Silva JA (ed) Floriculture, ornamental and plant biotechnology: advances and topical issues. Global Science Books, London, pp 84-98

Kusaba M (2004) RNA interference in crop plants. Curr Opin Biotech 15:139-143

Leegood RC (2007) A welcome diversion from photorespiration. Nat Biotech 25:539-540

Levee V, Garin E, Klimaszewska K, Seguin A (1999) Stable genetic transformation of white pine (Pinus strobus L.) after cocultivation of embryogenic tissues with Agrobacterium tumefaciens. Mol Breed 5:429-440

Levin JS, Thompson WF, Csinos AS, Stephenson MG, Weissinger AK (2005) Matrix attachment regions increase the efficiency and stability of RNA-mediated resistance to tomato spotted wilt virus in transgenic tobacco. Trans Res 14:193-206

Linnemann AK, Platts AE, Doggett N, Gluch A, Bode J, Krawetz SA (2007) Genomewide identification of nuclear matrix attachment regions: an analysis of methods. Biochem Soc Trans 35:612-617 
Lippman Z, Martienssen R (2004) The role of RNA interference in heterochromatic silencing. Nature 431:364-70

Makarevitch I, Svitashev SK, Somers DA (2003) Complete sequence analysis of transgene loci from plants transformed via microprojectile bombardment. Plant Mol Biol 52:421-432

Marathe R, Smith TH, Anandalakshmi R, Bowman LH, Fagard M, Mourrain P, Vaucheret H, Vance VB (2000) Plant viral suppressors of post-transcriptional silencing do not suppress transcriptional silencing. Plant J 22:51-59

Martienssen RA (2003) Maintenance of heterochromatin by RNA interference of tandem repeats. Nat Genet 35:213-214

Martienssen RA, Zaratiegui M, Goto DB (2005) RNA interference and heterochromatin in the fission yeast Schizosaccharomyces pombe. Trends Genet 21:450-456

Maximova S, Miller C, Antunez de Mayolo G, Pishak S, Young A, Guiltinan MJ (2003) Stable transformation of Theobroma cacao L. and influence of Matrix Attachment Regions on GFP expression. Plant Cell Rep 21:872-883

May BP, Lippman ZB, Fang Y, Spector DL, Martienssen RA (2005) Differential regulation of strand-specific transcripts from Arabidopsis centromeric satellite repeats. PLoS Genet 1:e79

McGinnis K, Murphy N, Carlson AR, Akula A, Akula C, Basinger H, Carlson M, Hermanson P, Kovacevic N, McGill MA, Seshadri V, Yoyokie J, Cone K, Kaeppler HF, Kaeppler SM, Springer NM (2007) Assessing the efficiency of RNA interference for maize functional genomics. Plant Physiol 143:1441-1451

Meneghini MD, Wu M, Madhani HD (2003) Conserved histone variant H2A.Z protects euchromatin from the ectopic spread of silent heterochromatin. Cell 112:725-736

Meyer P, Kartzke S, Niedenhoff I, Heidmann I, Bussmann K, Saedler H (1988) A genomic DNA segment from Petunia hybrida leads to increased transformation frequencies and simple integration patterns. Proc Natl Acad Sci USA 85:8568-8572

Mirkovitch J, Mirault M-E, Laemmli U (1984) Organisation of the higher-order chromatin loop: specific DNA attachment sites on nuclear scaffold. Cell 39:223-232

Mlynarova L, Hricova A, Loonen A, Nap JP (2003) The presence of a chromatin boundary appears to shield a transgene in tobacco from RNA silencing. Plant Cell 15:2203-2217

Mlynarova L, Jansen RC, Conner AJ, Stiekema WJ, Nap JP (1995) The MAR-mediated reduction in position effect can be uncoupled from copy number-dependent expression in transgenic plants. Plant Cell 7:599-609

Mlynarova L, Loonen A, Heldens J, Jansen RC, Keizer P, Stiekema WJ, Nap JP (1994) Reduced position effect in mature transgenic plants conferred by the chicken lysozyme matrix-associated region. Plant Cell 6:417-426

Mlynarova L, Loonen A, Mietkiewska E, Jansen RC, Nap JP (2002) Assembly of two transgenes in an artificial chromatin domain gives highly coordinated expression in tobacco. Genetics 160:727-740

Mourrain P, Beclin C, Elmayan T, Feuerbach F, Godon C, Morel JB, Jouette D, Lacombe AM, Nikic S, Picault N, Remoue K, Sanial M, Vo TA, Vaucheret H (2000) Arabidopsis SGS2 and SGS3 genes are required for posttranscriptional gene silencing and natural virus resistance. Cell 101:533-542

Muller A, Marins M, Kamisugi Y, Meyer P (2002) Analysis of hypermethylation in the RPS element suggests a signal function for short inverted repeats in de novo methylation. Plant Mol Biol 48:383-399

Nagy F, Morelli G, Fraley RT, Rogers SG, Chua NH (1985) Photoregulated expression of a pea $r b c S$ gene in leaves of transgenic plants. EMBO J 4:3063-3068

Niessen M, Thiruveedhi K, Rosenkranz R, Kebeish R, Hirsch H-J, Kreuzaler F, Peterhansel C (2007) Mitochondrial glycolate oxidation contributes to photorespiration in higher plants. J Exp Bot 58:2709-2715

Oh SJ, Jeong JS, Kim EH, Yi NR, Yi SI, Jang IC, Kim YS, Suh SC, Nahm BH, Kim JK (2005) Matrix attachment region from the chicken lysozyme locus reduces variability in transgene expression and confers copy number-dependence in transgenic rice plants. Plant Cell Rep 24:145-154 
Park YD, Papp I, Moscone EA, Iglesias VA, Vaucheret H, Matzke AJM, Matzke MA (1996) Gene silencing mediated by promoter homology occurs at the level of transcription and results in meiotically heritable alterations in methylation and gene activity. Plant J 9:183-194

Pathak RU, Rangaraj N, Kallappagoudar S, Mishra K, Mishra RK (2007) Boundary elementassociated factor $32 \mathrm{~B}$ connects chromatin domains to the nuclear matrix. Mol Cell Biol 27:4796-4806

Paul AL, Ferl RJ (1998) Higher order chromatin structures in maize and Arabidopsis. Plant Cell 10:1349-1359

Paulson JR, Laemmli UK (1977) The structure of histone-depleted metaphase chromosomes. Cell 12:817-828

Pecinka A, Kato N, Meister A, Probst AV, Schubert I, Lam E (2005) Tandem repetitive transgenes and fluorescent chromatin tags alter local interphase chromosome arrangement in Arabidopsis thaliana. J Cell Sci 118:3751-3758

Pederson T (2000) Half a century of "The Nuclear Matrix". Mol Biol Cell 11:799-805

Petersen K, Leah R, Knudsen S, Cameron-Mills V (2002) Matrix attachment regions (MARs) enhance transformation frequencies and reduce variance of transgene expression in barley. Plant Mol Biol 49:45-58

Phi-Van L, von Kries JP, Ostertag W, Stratling WH (1990) The chicken lysozyme 5 Matrix Attachment Region increases transcription from a heterologous promoter in heterologous cells and dampens position effects on the expression of transfected genes. Mol Cell Biol 10:2302-2307

Poljak L, Seum C, Mattioni T, Laemmli UK (1994) SARs stimulate but do not confer position independent gene expression. Nucleic Acids Res 22:4386-4394

Pwee KH, Webster CI, Gray JC (1994) HMG protein binding to an A/T-rich positive regulatory region of the pea plastocyanin gene promoter. Plant Mol Biol 26:1907-1920

Que QD, Wang HY, English JJ, Jorgensen RA (1997) The frequency and degree of cosuppression by sense chalcone synthase transgenes are dependent on transgene promoter strength and are reduced by premature nonsense codons in the transgene coding sequence. Plant Cell 9:1357-1368

Ragoczy T, Bender MA, Telling A, Byron R, Groudine M (2006) The locus control region is required for association of the murine $b$-globin locus with engaged transcription factories during erythroid maturation. Genes Dev 20:1447-1457

Richards EJ, Elgin SC (2002) Epigenetic codes for heterochromatin formation and silencing: rounding up the usual suspects. Cell 108:489-500

Robertson D (2004) VIGS vectors for gene silencing: many targets, many tools. Ann Rev Plant Biol 55:495-519

Rozowsky JS, Newburger D, Sayward F, Wu J, Jordan G, Korbel JO, Nagalakshmi U, Yang J, Zheng D, Guigo R, Gingeras TR, Weissman S, Miller P, Snyder M, Gerstein MB (2007) The DART classification of unannotated transcription within the ENCODE regions: associating transcription with known and novel loci. Genome Res 17:732-745

Rudd S, Frisch M, Grote K, Meyers BC, Mayer K, Werner T (2004) Genome-wide in silico mapping of scaffold/matrix attachment regions in Arabidopsis suggests correlation of intragenic scaffold/matrix attachment regions with gene expression. Plant Physiol 135:715-722

Sabo PJ, Kuehn MS, Thurman R, Johnson BE, Johnson EM, Cao H, Yu M, Rosenzweig E, Goldy J, Haydock A, Weaver M, Shafer A, Lee K, Neri F, Humbert R, Singer MA, Richmond TA, Dorschner MO, McArthur M, Hawrylycz M, Green RD, Navas PA, Noble WS, Stamatoyannopoulos JA (2006) Genome-scale mapping of DNase I sensitivity in vivo using tiling DNA microarrays. Nat Methods 3:511-518

Sandhu JS, Webster CI, Gray JC (1998) A/T-rich sequences act as quantitative enhancers of gene expression in transgenic tobacco and potato plants. Plant Mol Biol 37:885-896

Sarcinella E, Zuzarte PC, Lau PNI, Draker R, Cheung P (2007) Monoubiquitylation of H2A.Z distinguishes its association with euchromatin or facultative heterochromatin. Mol Cell Biol 27:6457-6468

Sawasaki T, Takahashi M, Goshima N, Morikawa H (1998) Structures of transgene loci in transgenic Arabidopsis plants obtained by particle bombardment: junction regions can bind to nuclear matrices. Gene 218:27-35 
Schoffl F, Schroder G, Kliem M, Rieping M (1993) An SAR-sequence containing 395 bp-DNA fragment mediates enhanced, gene-dosage-correlated expression of a chimaeric heat shock gene in transgenic tobacco plants. Trans Res 2:93-100

Sidorenko L, Bruce W, Maddock S, Tagliani L, Li XG, Daniels M, Peterson T (2003) Functional analysis of two matrix attachment region (MAR) elements in transgenic maize plants. Trans Res 12:137-154

Singh GB, Kramer JA, Krawetz SA (1997) Mathematical model to predict regions of chromatin attachment to the nuclear matrix. Nucleic Acids Res 25:1419-1425

Slatter RE, Dupree P, Gray JC (1991) A scaffold-associated DNA region is located downstream of the pea plastocyanin gene. Plant Cell 3:1239-1250

Soppe WJJ, Jasencakova Z, Houben A, Kakutani T, Meister A, Huang MS, Jacobsen SE, Schubert I, Fransz PF (2002) DNA methylation controls histone H3 lysine 9 methylation and heterochromatin assembly in Arabidopsis. EMBO J 21:6549-6559

Spiker S, Murray MG, Thompson WF (1983) DNase I sensitivity of transcriptionally active genes in intact nuclei and isolated chromatin of plants. Proc Natl Acad Sci USA 80:815-819

Stam M, Mol JNM, Kooter JM (1997) The silence of genes in transgenic plants. Ann Bot 79:3-12

Stief A, Winter DM, Stratling WH, Sippel AE (1989) A nuclear DNA attachment element mediates elevated and position-independent gene activity. Nature 341:343-345

Taddei A, Hediger F, Neumann FR, Gasser SM (2004) The function of nuclear architecture: a genetic approach. Ann Rev Genet 38:305-345

Taddei A, Van Houwe G, Hediger F, Kalck V, Cubizolles F, Schober H, Gasser SM (2006) Nuclear pore association confers optimal expression levels for an inducible yeast gene. Nature 441:774-778

Takano M, Egawa H, Ikeda JE, Wakasa K (1997) The structures of integration sites in transgenic rice. Plant J 11:353-361

Talbert PB, Henikoff S (2006) Spreading of silent chromatin: inaction at a distance. Nat Rev Genet 7:793-803

Tamaru H, Selker EU (2001) A histone H3 methyltransferase controls DNA methylation in Neurospora crassa. Nature 414:277-283

Tang G, Galili G (2004) Using RNAi to improve plant nutritional value: from mechanism to application. Trends Biotech 22:463-469

Tariq M, Paszkowski J (2004) DNA and histone methylation in plants. Trends Genet 20:244-251

Tetko IV, Haberer G, Rudd S, Meyers B, Mewes HW, Mayer KF (2006) Spatiotemporal expression control correlates with intragenic scaffold matrix attachment regions (S/MARs) in Arabidopsis thaliana. PLoS Comp Biol 2:e21

Thompson WF, Spiker S, Allen GC (2006) Matrix attachment regions. In: Grasser KD (ed) Regulation of transcription in plants. Blackwell, Oxford, pp 350

Ulker B, Allen GC, Thompson WF, Spiker S, Weissinger AK (1999) A tobacco matrix attachment region reduces the loss of transgene expression in the progeny of transgenic tobacco plants. Plant J 18:253-263

Vain P, James VA, Worland B, Snape JW (2002) Transgene behaviour across two generations in a large random population of transgenic rice plants produced by particle bombardment. Theor Appl Genet 105:878-889

Vaistij FE, Jones L, Baulcombe DC (2002) Spreading of RNA targeting and DNA methylation in RNA silencing requires transcription of the target gene and a putative RNA-dependent RNA polymerase. Plant Cell 14:857-867

Valenzuela L, Kamakaka RT (2006) Chromatin Insulators. Ann Rev Genet 40:107-138

Vain P, Afolabi AS, Worland B, Snape JW (2003) Transgene behaviour in populations of rice plants transformed using a new dual binary vector system: pGreen/pSoup. Theor Appl Genet 107:210-217

Van Blokland R, ten Lohuis M, Meyer P (1997) Condensation of chromatin in transcriptional regions of an inactivated plant transgene: evidence for an active role of transcription in gene silencing. Mol Gen Genet 257:1-13 
Van der Geest AHM, Hall GE, Spiker S, Hall TC (1994) The $\beta$-phaseolin gene is flanked by matrix attachment regions. Plant J 6:413-423

Van Leeuwen W, Mlynarova L, Nap JP, van der Plas LH, van der Krol AR (2001) The effect of MAR elements on variation in spatial and temporal regulation of transgene expression. Plant Mol Biol 47:543-554

Vaucheret H (1993) Identification of a general trans-silencer for $19 \mathrm{~S}$ and $35 \mathrm{~S}$ promoters in a transgenic tobacco plant: 90 bp of homology in the promoter sequences are sufficient for transinactivation. C R Acad Sci Paris Life Sci 316:1471-1483

Vaucheret H, Elmayan T, Thierry D, van der Geest A, Hall T, Conner AJ, Mlynarova L, Nap JP (1998) Flank matrix attachment regions (MARs) from chicken, bean, yeast or tobacco do not prevent homology-dependent trans-silencing in transgenic tobacco plants. Mol Gen Genet 259:388-392

Vaucheret H, Nussaume L, Palauqui JC, Quillere I, Elmayan T (1997) A transcriptionally active state is required for post-transcriptional silencing (cosuppression) of nitrate reductase host genes and transgenes. Plant Cell 9:1495-1504

Vega-Palas MA, Ferl RJ (1995) The Arabidopsis Adh gene exhibits diverse nucleosome arrangements within a small DNase I-sensitive domain. Plant Cell 7:1923-1932

Volpe TA, Kidner C, Hall IM, Teng G, Grewal SI, Martienssen RA (2002) Regulation of heterochromatic silencing and histone H3 lysine-9 methylation by RNAi. Science 297:1833-1837

Washietl S, Pedersen JS, Korbel JO, Stocsits C, Gruber AR, Hackermuller J, Hertel J, Lindemeyer M, Reiche K, Tanzer A, Ucla C, Wyss C, Antonarakis SE, Denoeud F, Lagarde J, Drenkow J, Kapranov P, Gingeras TR, Guigo R, Snyder M, Gerstein MB, Reymond A, Hofacker IL, Stadler PF (2007) Structured RNAs in the ENCODE selected regions of the human genome. Genome Res 17:852-864

Waterhouse PM, Helliwell CA (2003) Exploring plant genomes by RNA-induced gene silencing. Nat Rev Genet 4:29-38

Weintraub H, Groudine M (1976) Chromosomal subunits in active genes have an altered conformation. Science 193:848-856

Wong MM, Cox LK, Chrivia JC (2007) The chromatin remodeling protein, SRCAP, Is critical for deposition of the histone variant H2A.Z at promoters. J Biol Chem 282:26132-26139

Zaratiegui M, Irvine DV, Martienssen RA (2007) Noncoding RNAs and gene silencing. Cell 128:763-776

Zhao T, Palotta M, Langridge P, Prasad M, Graner A, Schulze-Lefert P, Koprek T (2006) Mapped Ds/T-DNA launch pads for functional genomics in barley. Plant J 47:811-826

Zilberman D, Cao X, Johansen LK, Xie Z, Carrington JC, Jacobsen SE (2004) Role of Arabidopsis ARGONAUTE4 in RNA-directed DNA methylation triggered by inverted repeats. Curr Biol $14: 1214-1220$ 